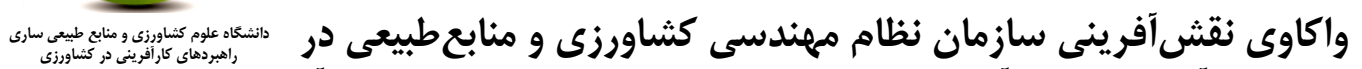

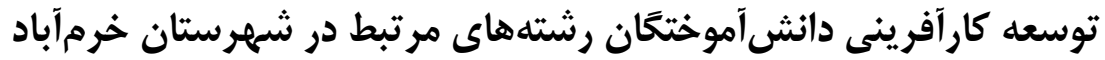

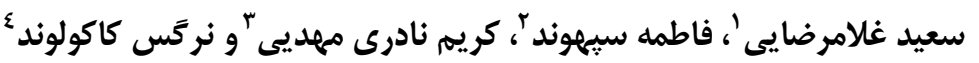

1- استاديار كروه توسعه روستايى، دانشخاه لرستان، (نويسنده مسوول: sgholamrezai@ gmail.com

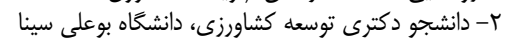

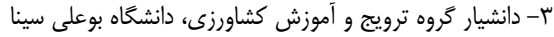

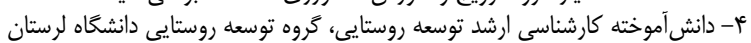

تاريخ دريافت:

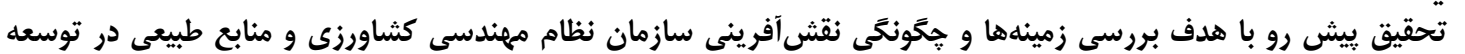

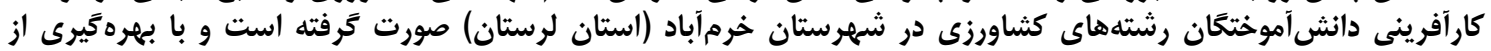

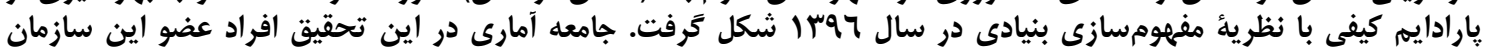

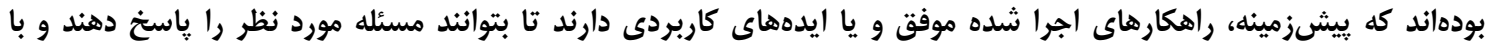

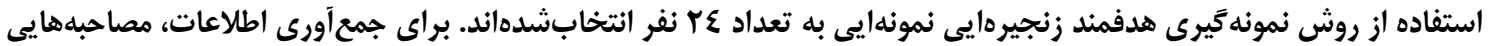

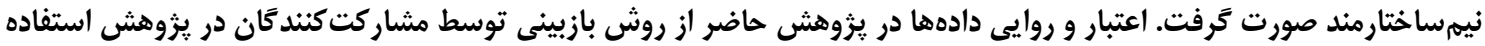

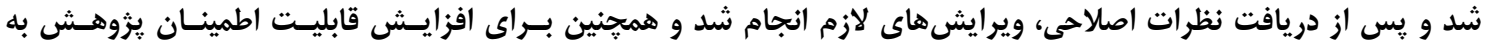

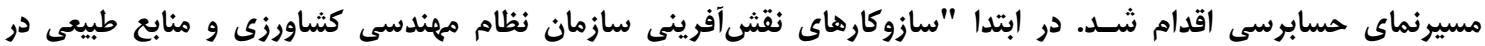

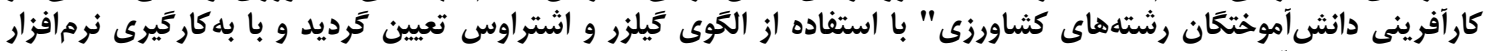

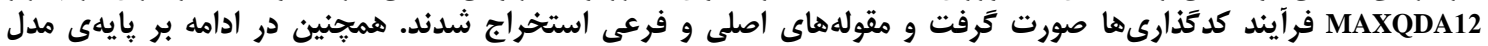

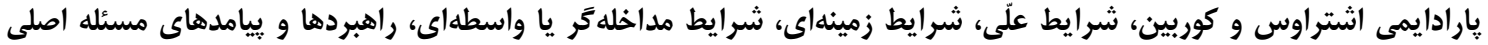

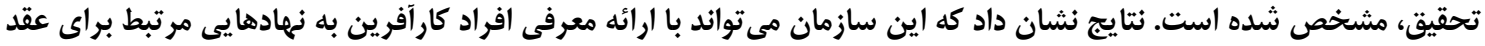

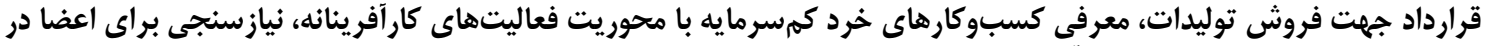

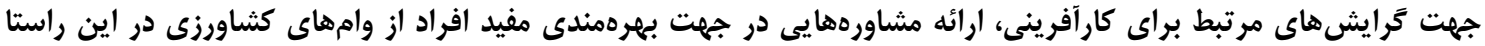
موفق تر عمل كند.

وازههاى كليدى: نظام مهندسى كثاورزى و منابع طبيعى، توسعه كار آفرينى، دانشآموختكان، لرستان

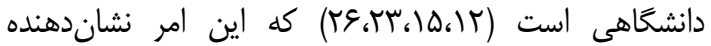

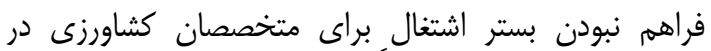

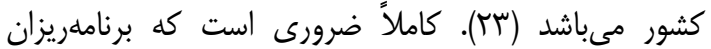

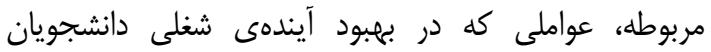

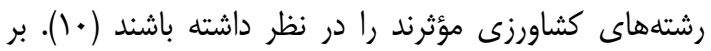

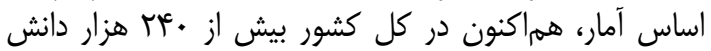

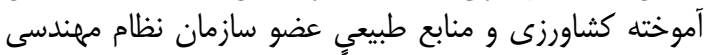

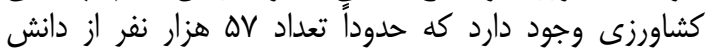

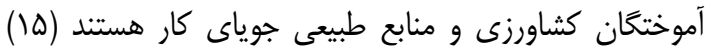

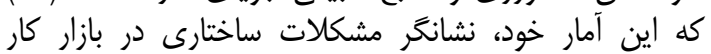

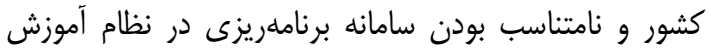

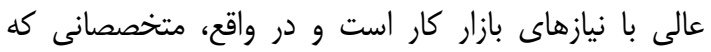

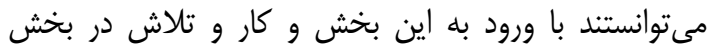

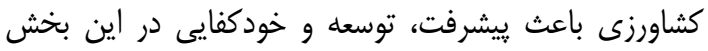

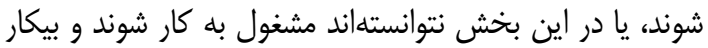

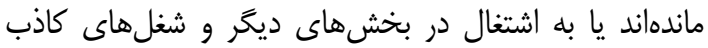

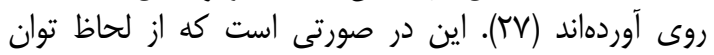

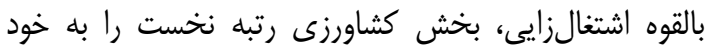

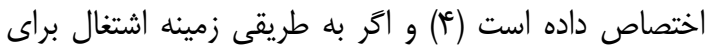

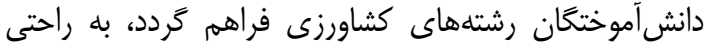

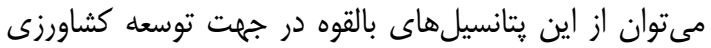

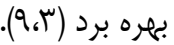

مقدمه

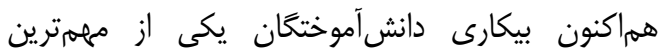

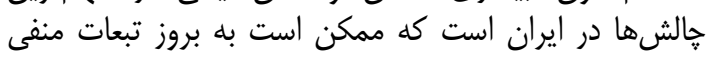

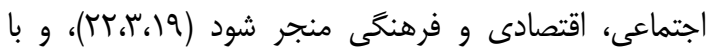

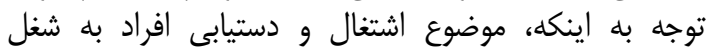

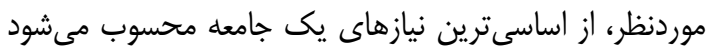

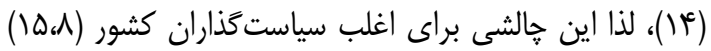

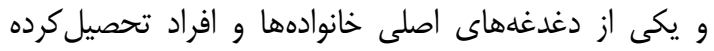

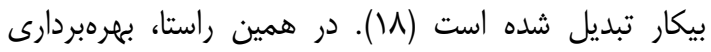

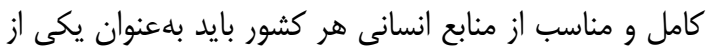

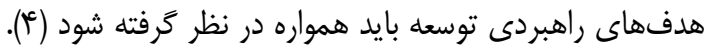

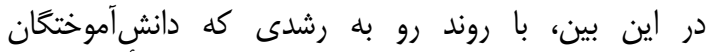

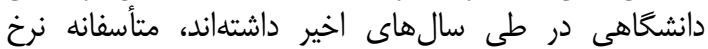

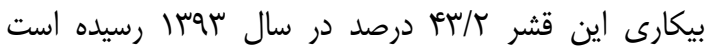

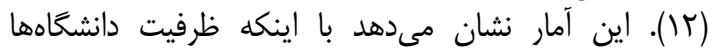

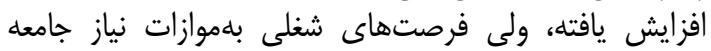

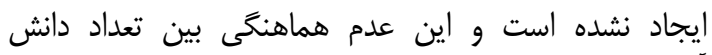

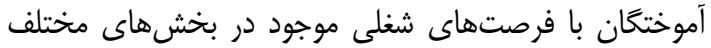

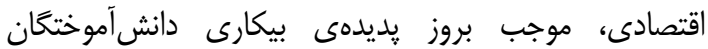

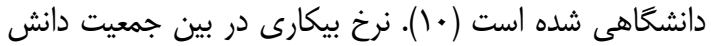

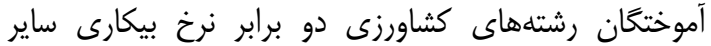

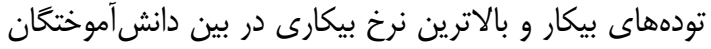


همكارىهاى علمى با مراكز آموزشى و يزوهشى كشورهاى

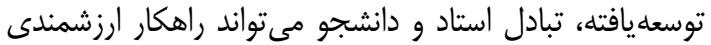

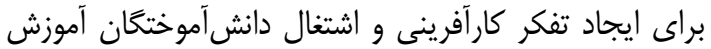

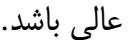
"سازمان نظاممهندسى كشاورزى و منابع طبيعى" بزركترين الشين

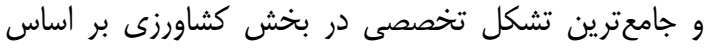

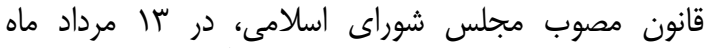

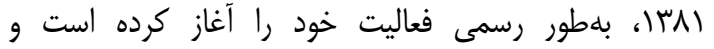

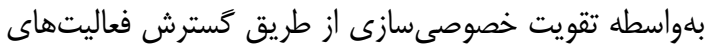

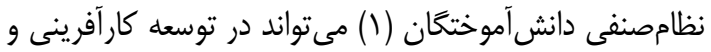

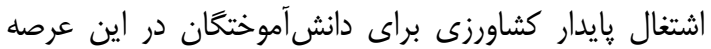

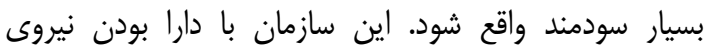

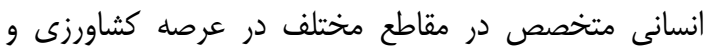

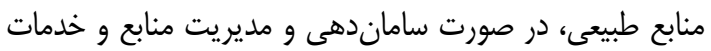

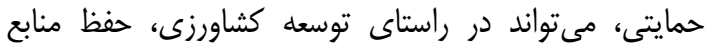

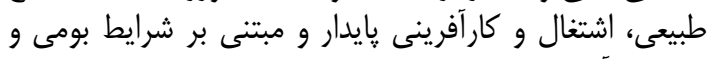

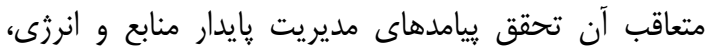

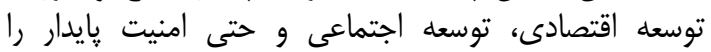

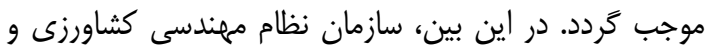

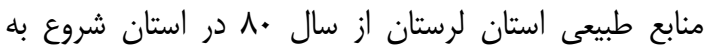

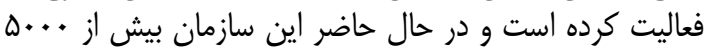

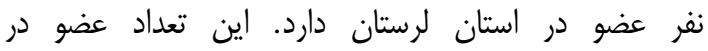

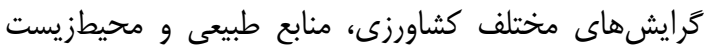

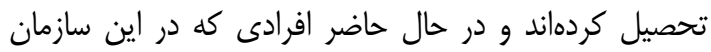

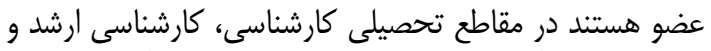

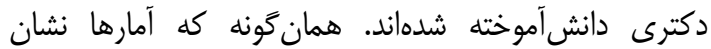

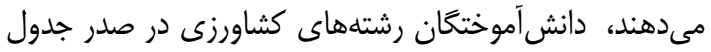

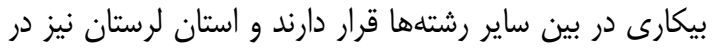

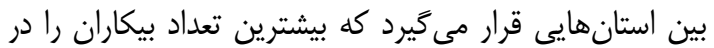

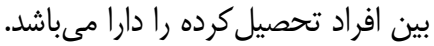

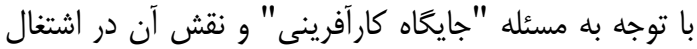

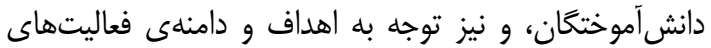

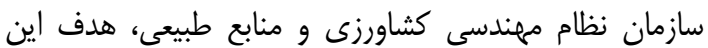

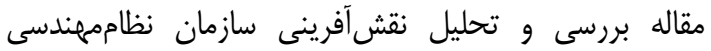
كشاورزى و منابع طبيعى در توسعه كار آفرينى دانشآسآموختانان

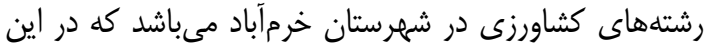

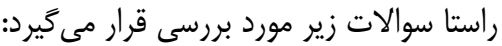

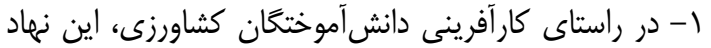

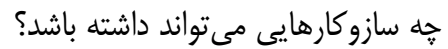

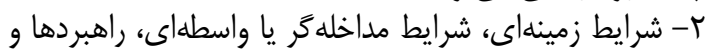
ييامدهاى مسئله اصلى تحقيق كدايط مدائد؟

\section{مواد و روشها}

تحقيق حاضر از لحاظ هدف، كاربردى و ودر كار كروه

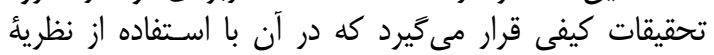

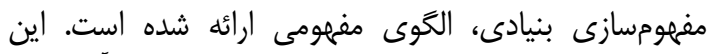

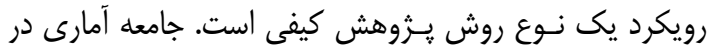

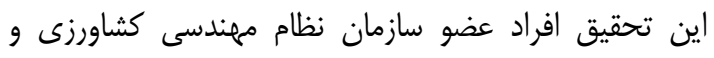

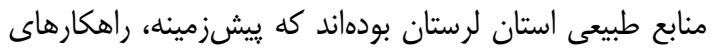

بـراى كاهـش ميـزان بيـكارى جوانـان و دانش آموختخان،

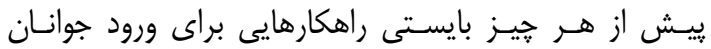

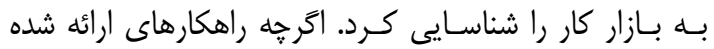

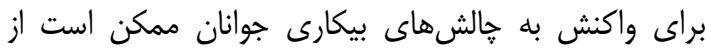

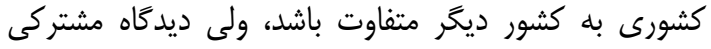

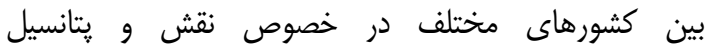

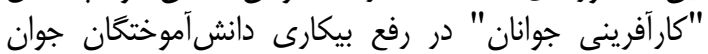

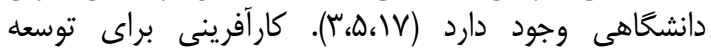

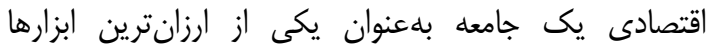

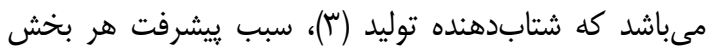

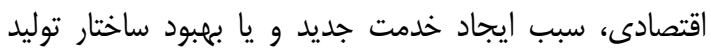

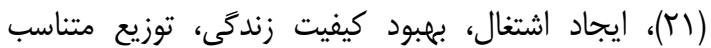

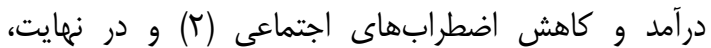

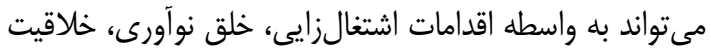

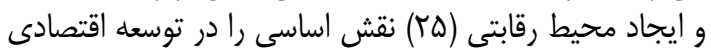

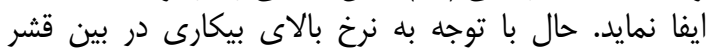

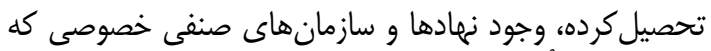

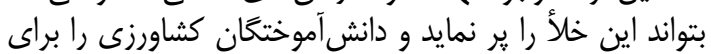

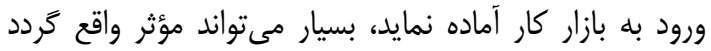

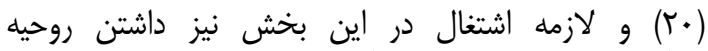

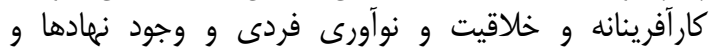

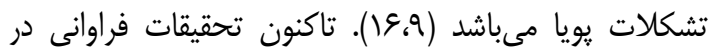

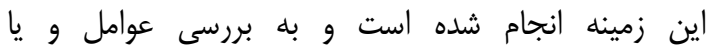

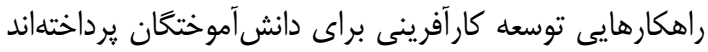

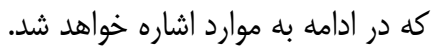

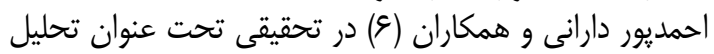

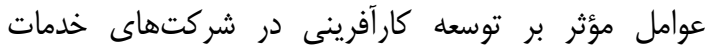

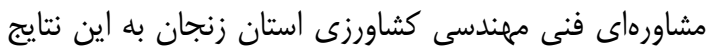

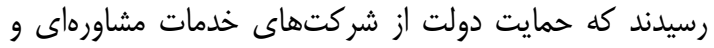

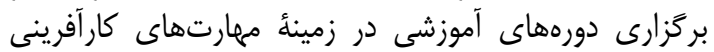

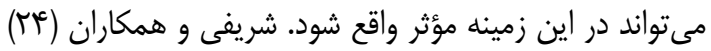

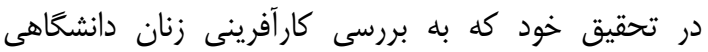

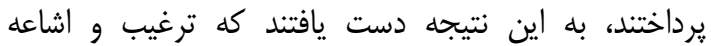

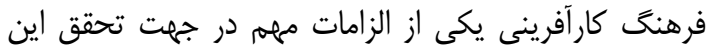

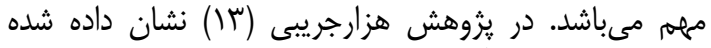

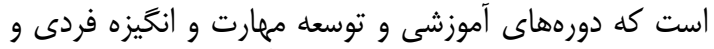

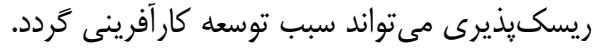

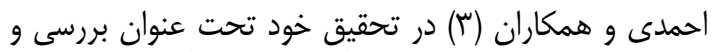

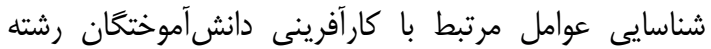

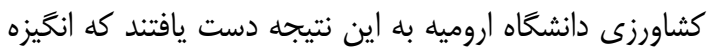

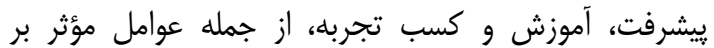

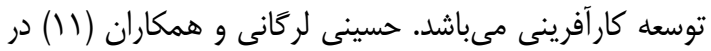

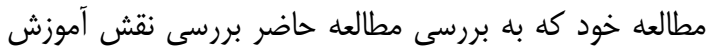

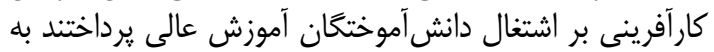

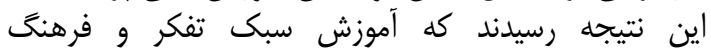

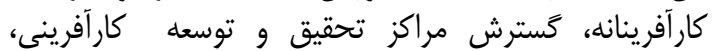

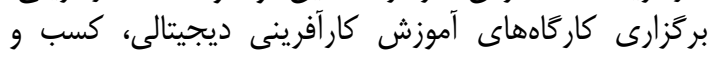

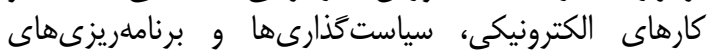

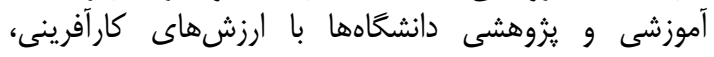


كدگذارى بر اساس سه روش كدگذارى باز، محورى و

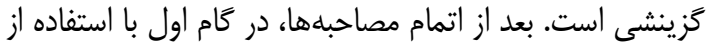

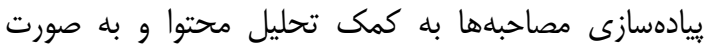

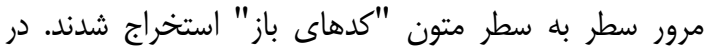

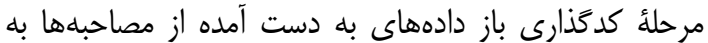

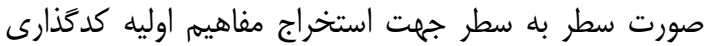

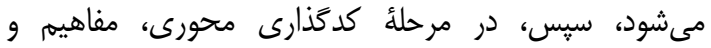

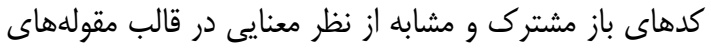
عمده با استفاده از نرمافزار

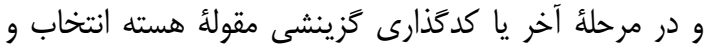

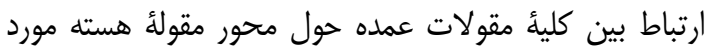

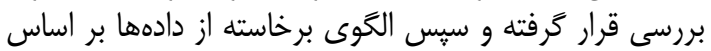

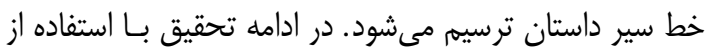

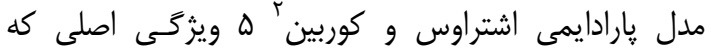

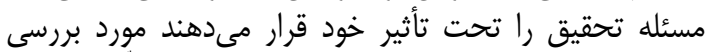

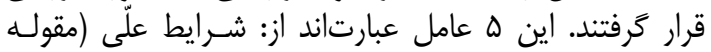

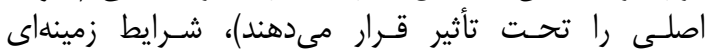

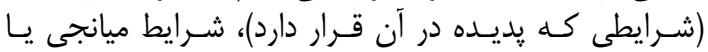

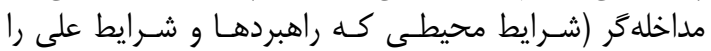

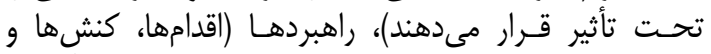

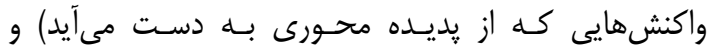

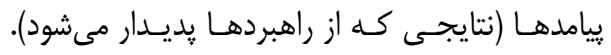

\section{نتايج و بحث}

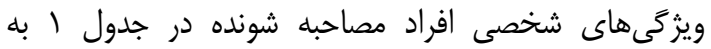
تفكيك نشان داده شده است.

Table 1. Demographic Characteristics of Interviewees

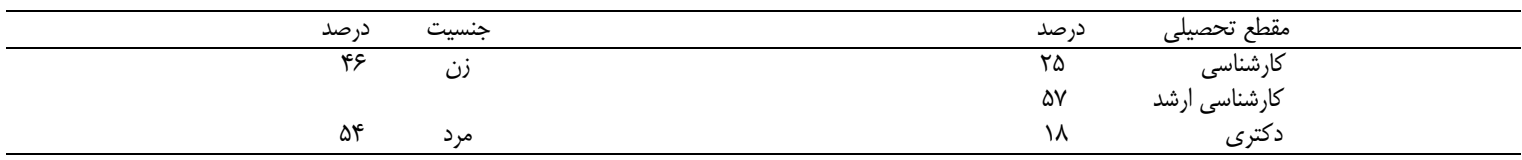

اتمام مصاحبهها، در كام اول با استفاده از زيادهسازى

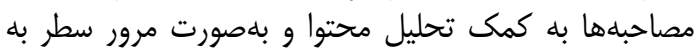

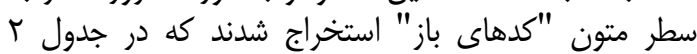

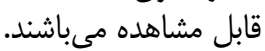

اجرا شده موفق و يا ايدههاى كاربردى دارند تا بتوانند مسئله

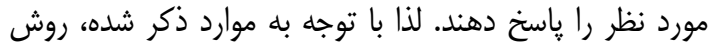

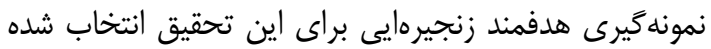

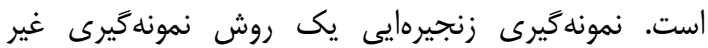

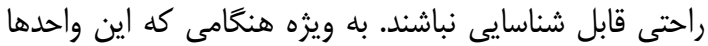

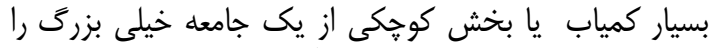

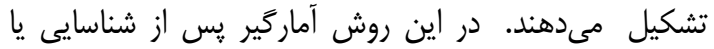

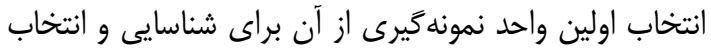

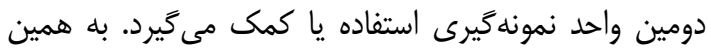

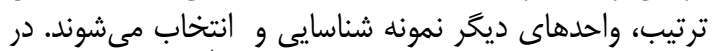

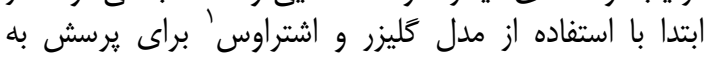

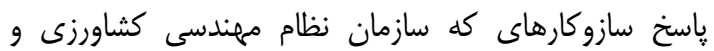

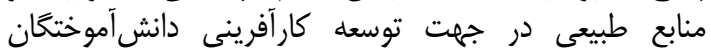

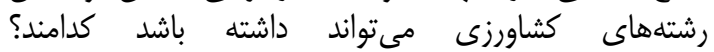
مصاحبههايى صورت گرفت كه مصاحبهها با سؤالات كلى نلى و

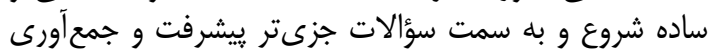

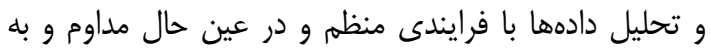

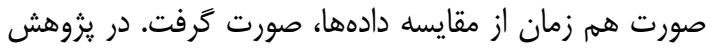

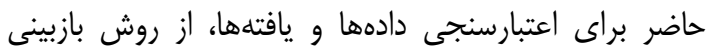

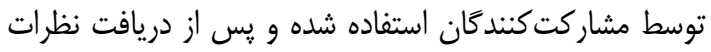

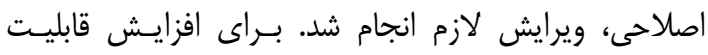

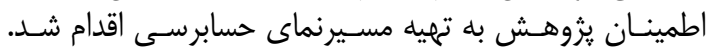

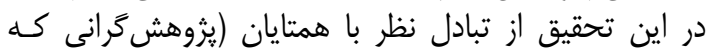

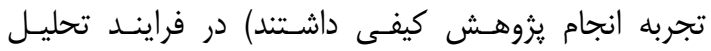

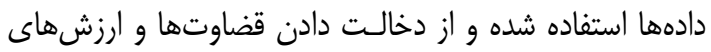

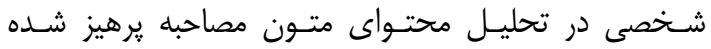

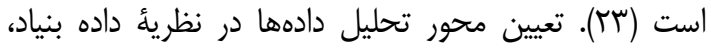

جدول 1- ويثزى هاى دموگرافيكى افراد مصاحبهشونده

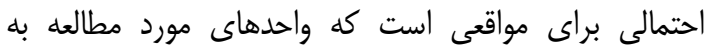

براى يافتن ياسخ اين سؤال كه "سازمان نظام مهندسى كاري

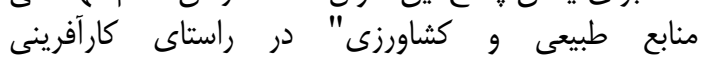

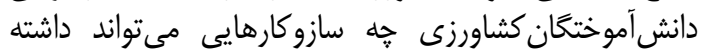

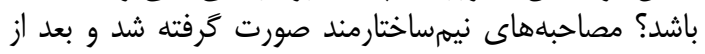


Table 2. Open Codes (Results of Primary content Analysis of the interviews)

جدول r- كدهاى باز (نتايج حاصل تحليل محتواى اوليه مصاحبهها)

\begin{tabular}{|c|}
\hline \\
\hline 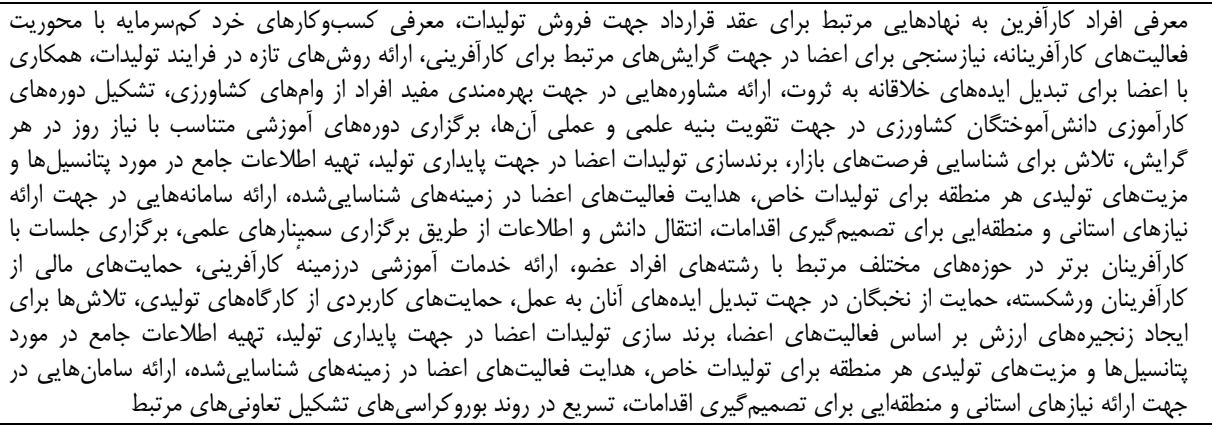 \\
\hline
\end{tabular}

بديدمحورى

استخراج كدگذارى محورى و و كدگذارى گزينشى توسط

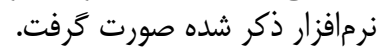

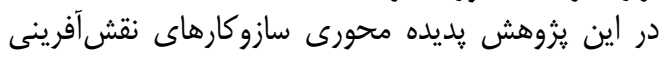

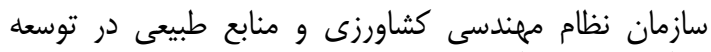

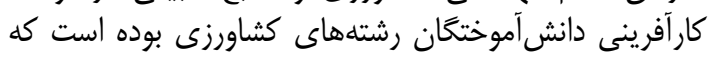
از تحليل مصاحبهها توسط نرمافزار

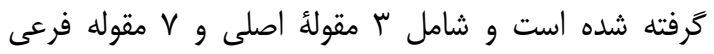

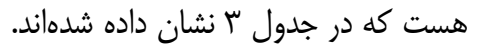

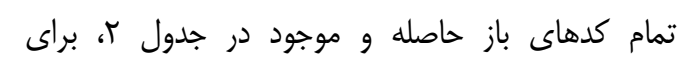

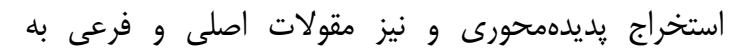

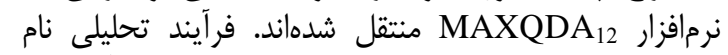

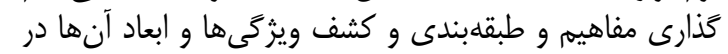

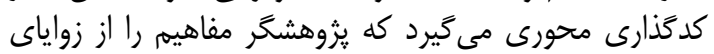

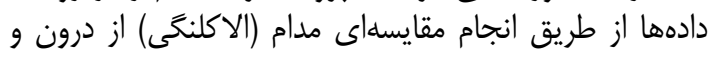

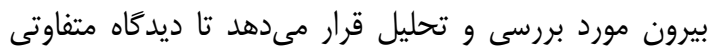
نسبت به اهميت و جايكاه مفاهيه كسب كند ور ور در اين تحقيق

Table 3. Extracted Categories and Subcategories

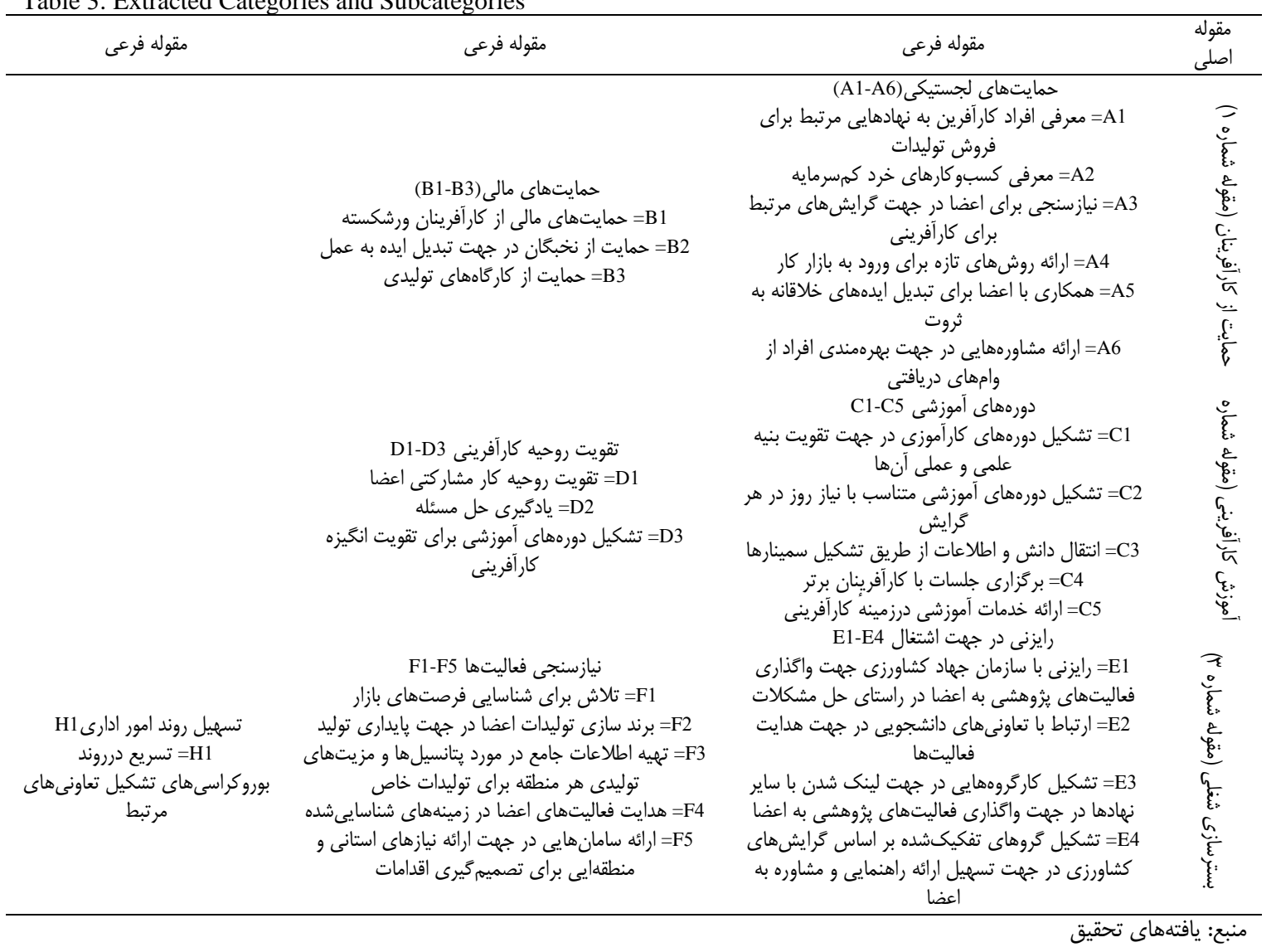


در جهت ارائه نيازهاى استانى و منطقهاى براى تصميهزيرى

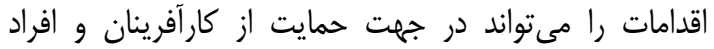

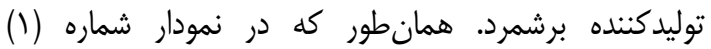
بلهنوان خروجى نرمافزار

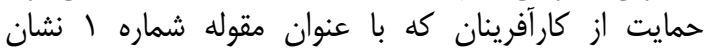

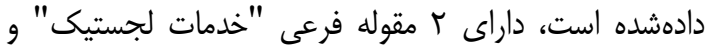

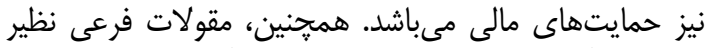

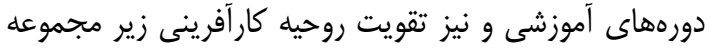

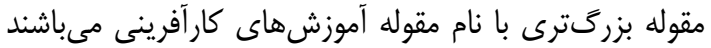

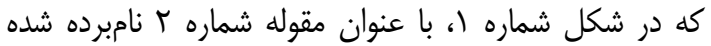

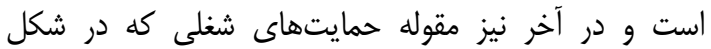

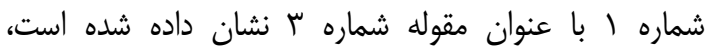

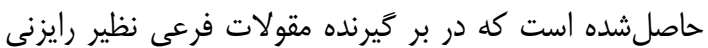

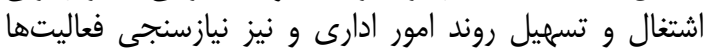
مىباشد.
مصاحبهشوندگًان اظهار داشتند كه گَاها افراد براى دريافت وام اقدام مىنمايند ولى تصميم درستى دارئ براى هزينه

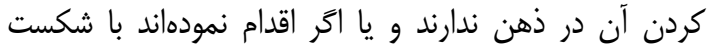

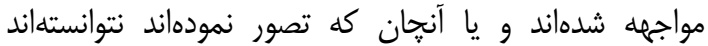

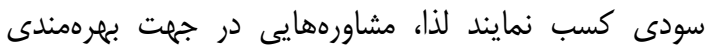

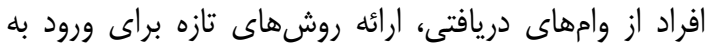

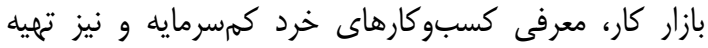
اطلاعات جامع در مورد يتانسيلها و و مزيتهاى إنى توليدى هر

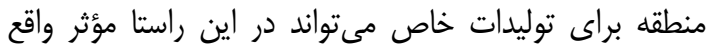

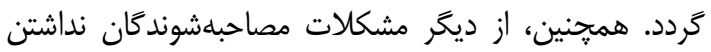

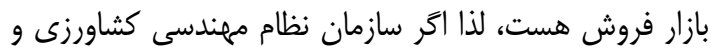

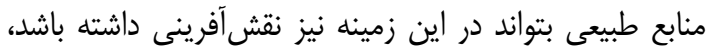

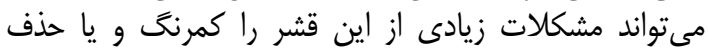

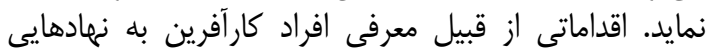

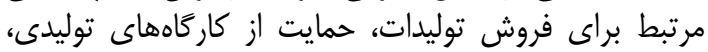

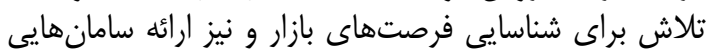

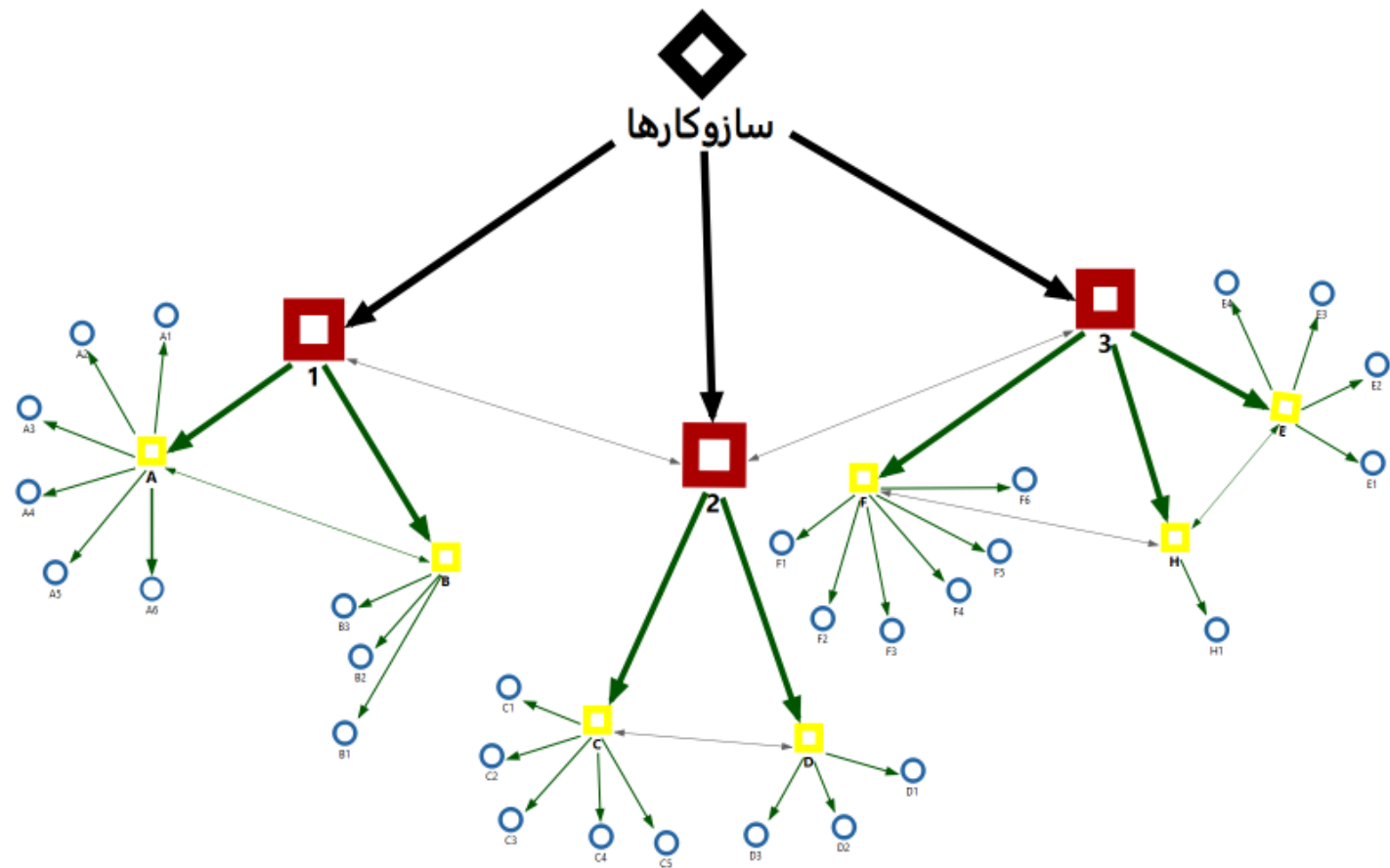

شكل ا - سازوكارهاى نقش آفرينى سازمان نظام مهندسى كشاورزى و منابع طبيعى در توسعه كارآفرينى دانش آموختكان رشتههاى مرتبط

Figure 1. Strategies for Role Playing of ANRE in development of entrepreneurship in related graduates

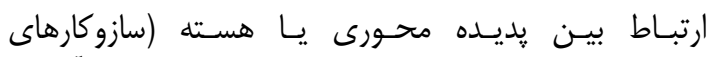

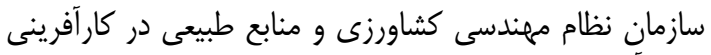

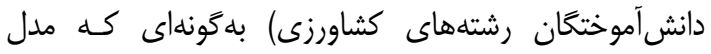

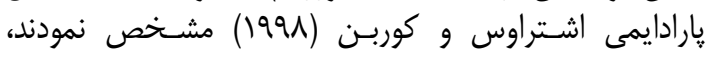

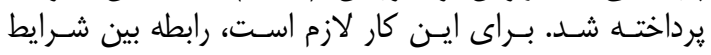

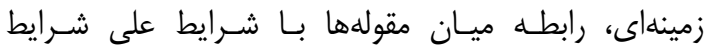

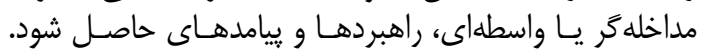
شر ايط على مدلى نقشآفرينى سازمان نظى نظام مهندسى كشاورزى و منابع

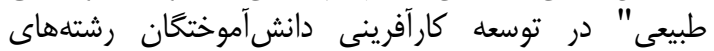

در ادامه تحقيق بـا استفاده از مدل ثاراديميك اشتراوس و

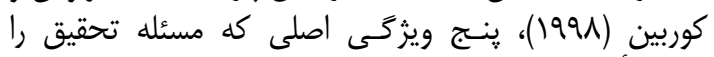

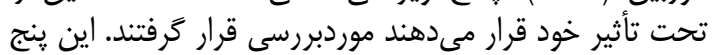

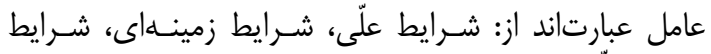

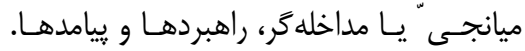

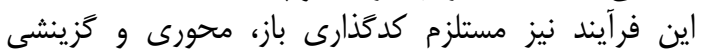

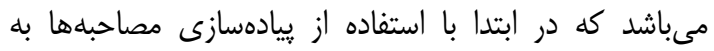

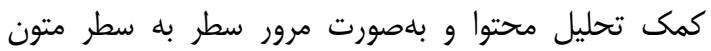

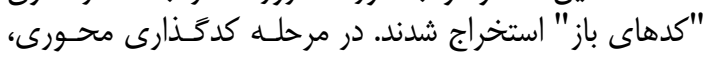

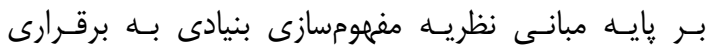




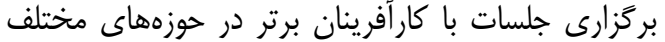

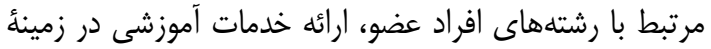

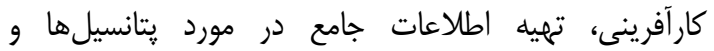

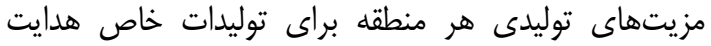

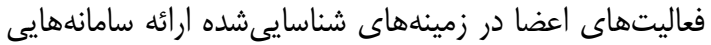

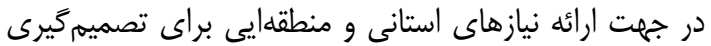
اقدامات بهعنوان راهبردهاى مناسب إناني تبيين شدهاند.

ييامدهات تسريع در روند تشكيل تعاونىها و شركت مشاورهاى هارها در

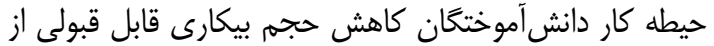

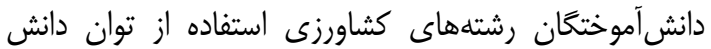

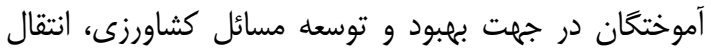

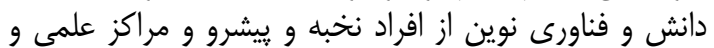

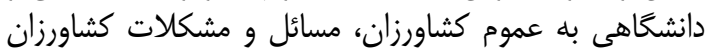

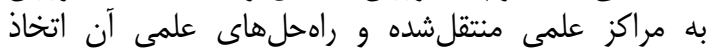

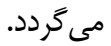
در نهايت، بر اساس تحليل دادهها شرايط و تعاملات ابعاد

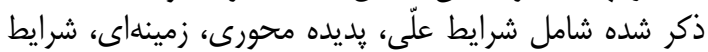

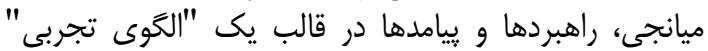
برخاسته از دادهها در شكل شماره r ت ترسيمشده است.
كشاورزى را بلهعنوان بديدة مورد مطالعه تبيين مى كند. اين

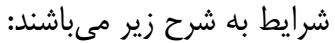

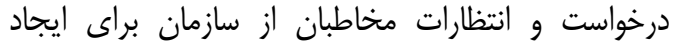

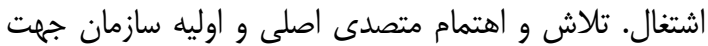

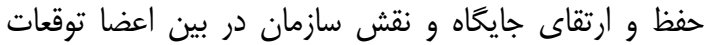

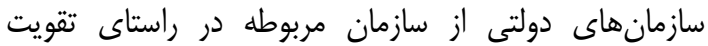
نقشآرينى در اشتغال و كارآفرينى دانى

شر ايط مداخله

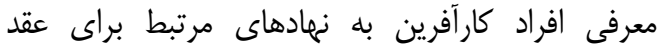

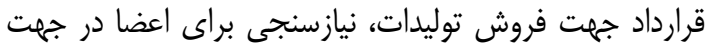

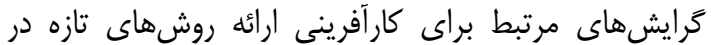

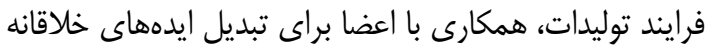

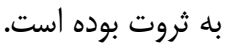

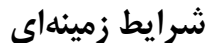

بيكارى مزمن و شديد دانشآموختكان كشاورزى، فراوانى

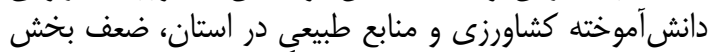

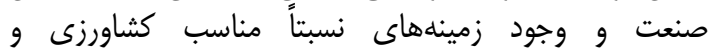

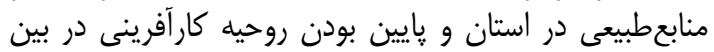

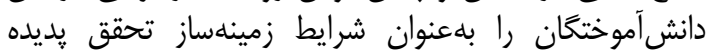

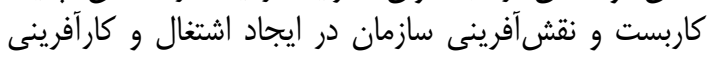

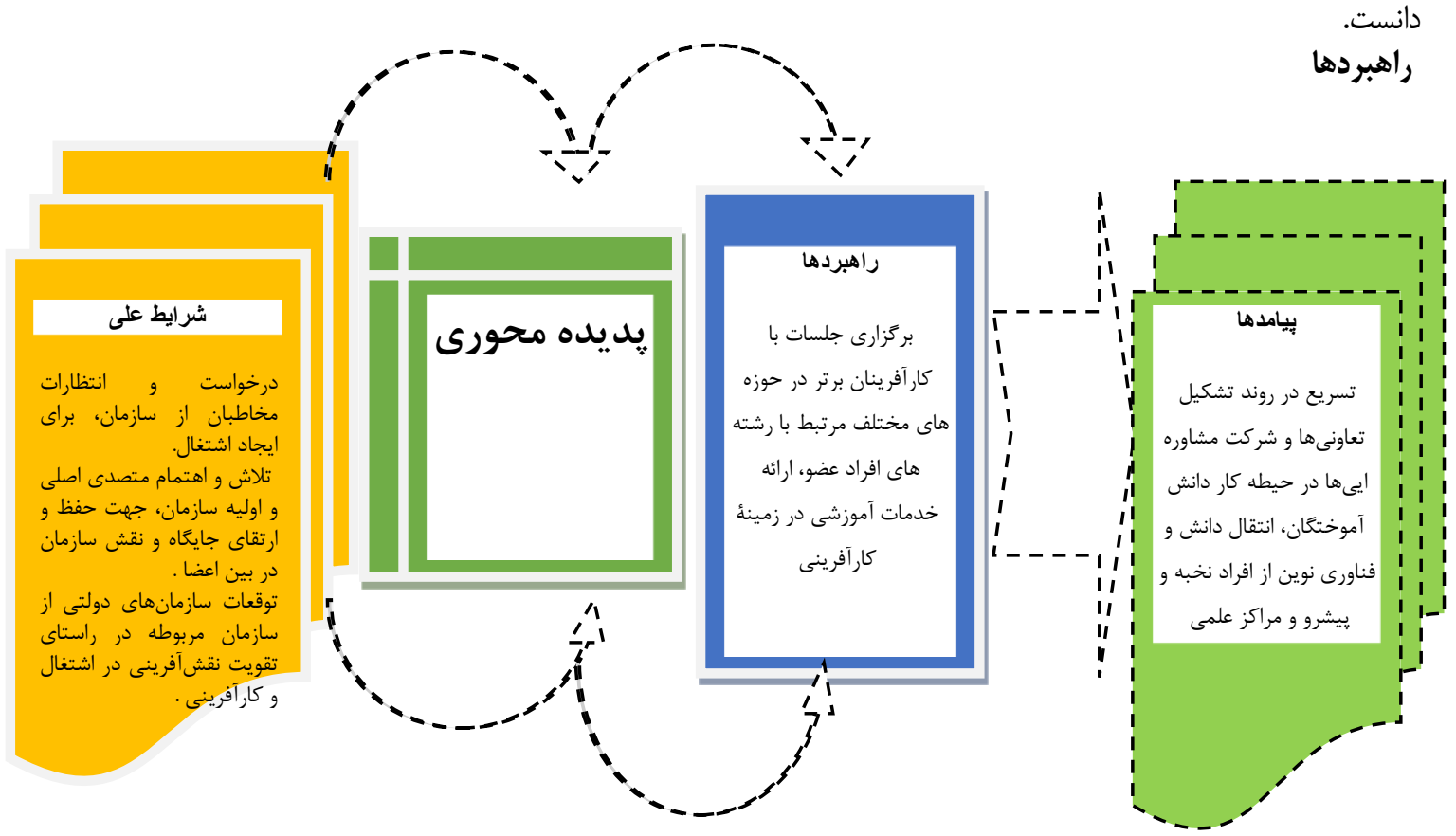

شكل r- شـرايط على، شـرايط زمينهاى، راهبردهـا و ييامدهاى براى توسعه كار آفرينى سازمان نظام مهندسى كشاورزى و منابع طبيعى براى

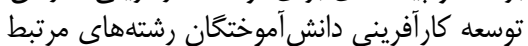

Figure 2. Casual Conditions, Contextual Conditions, Strategies and Outcomes for development of entrepreneurship in related graduates of ANRE O 


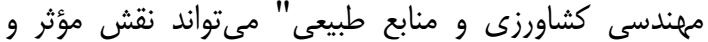

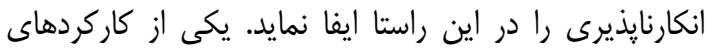

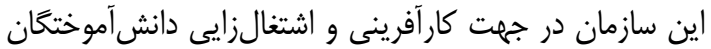

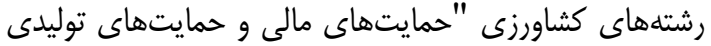

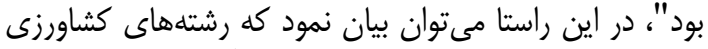

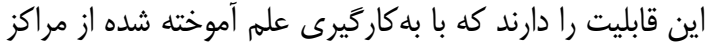

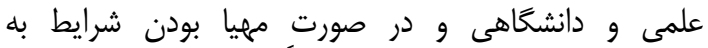

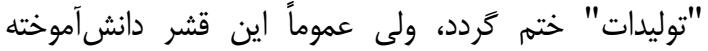

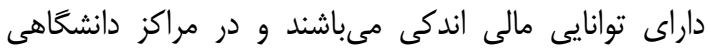

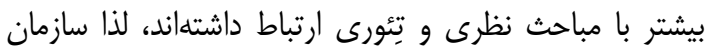

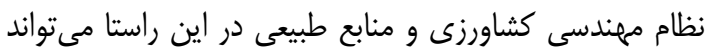

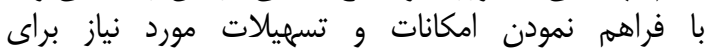

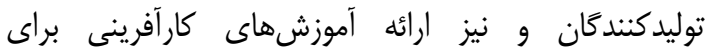

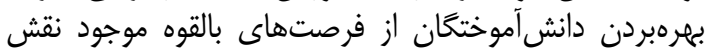

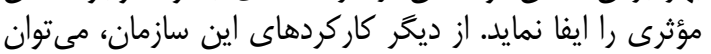

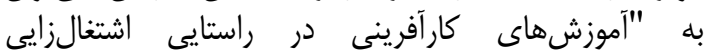

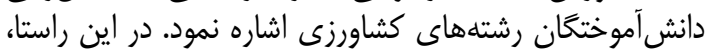

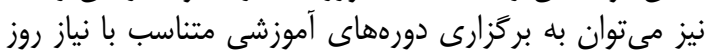

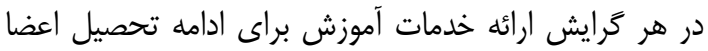

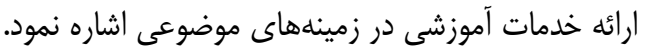

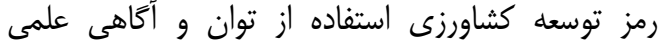

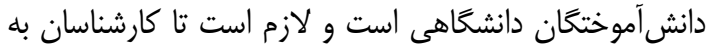

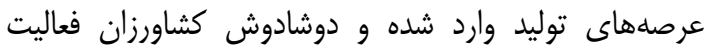

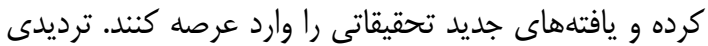

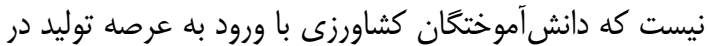

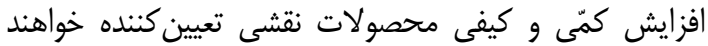

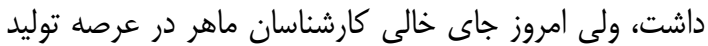

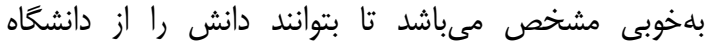

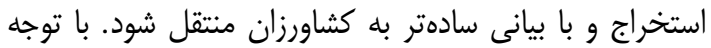

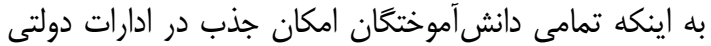

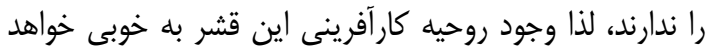

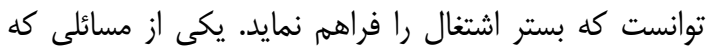

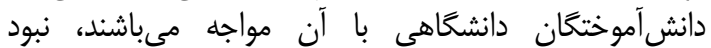

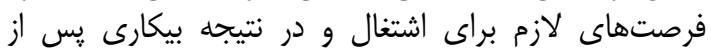

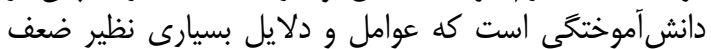

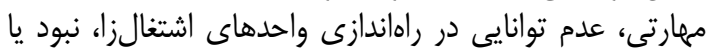

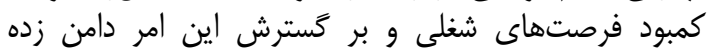

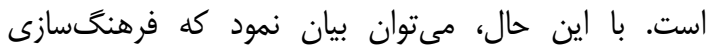

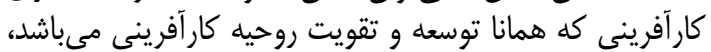

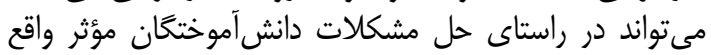
گردد. همان طور كه نتايج اين تحقيق نشان داد داد "سازمان نظام أنام

1. Ashrafi A. 2017. Tasks of the Agricultural and Islamic Republic of Iran: 12-13

2. Aghamohamadi, J. and H. Abdolahi. 2014. Analysis of the role of education in the development and promotion of entrepreneurship. Journal Approach, 25: 75-87

3. Ahmadi, F., S.H. Nabizadeh and S. Ahmadi. 2016. A Survey on the Factors Affecting the Entrepreneurship of Agricultural Graduates, Agricultural Economics and Development, 26: 253-274.

4. Ardakani, B. and M. Ghanbari. 2011. Creating employment in agriculture and removing barriers. National Conference on Employment of Agricultural and Natural Resources graduates. Tehran, Tarbiat Modares University, 23-28

5. Ansari, M. and B. Amel. 2014. Environmental barriers of student and graduate orientation towards entrepreneurship. Quarterly Journal of Research and Planning in Higher Education, 72: 117-141

6. Ahmadpour darani, M., H. Nik bin and A. karimi. 2011. Effective factors on entrepreneurship development in Zanjan Agricultural Engineering Engineering Consultant Services. Research on Economic and Agricultural Development of Iran, 42: 535-54.

7. Ahmadi, F., S.H. Nabe zadeh and S. Ahmadi. 2015. Investigating the Factors Affecting the Entrepreneurship of Agricultural Graduates. Agricultural Economics and Development, 24: 253-274

8. Barani, S.H., Z. Athari and K. Zarafshan. 2009. Study of the reasons for entrepreneurship tendency of scientific-applied agricultural students (Case Study: Kermanshah province). Quarterly of Entrepreneurship Development, 2: 73-99.

9. Ghasemi, S., S. Bahramian and M. Ahmadwond. 2014. Effective Factors on Entrepreneurship Capacity and Post-Graduate Employment (Case Study: Agricultural Undergraduate Students at Yasouj University). Entrepreneurship and Agriculture, 1:1-19.

10. Haji Wand, R. and B. Khosravi Pour. 2011. Employment of Agricultural Graduates: Requirements: Challenges, Solutions. National Conference on Employment of Agricultural and Natural Resources graduates. Tehran, Tarbiat Modares University: 45-50

11. Hosseini Lorgani, M.R., M. Aram razi and S. Rezai. 2008. Entrepreneurship education in the new millennium; Infrastructure for the employment of graduates of higher education. Research and Planning in Higher Education, 14: 119-137.

12. Hosseini, S.J.F., H. Ahmadi and M. Omidi Najafabadi. 2011. The perceptions of graduate students about factors influencing the extension of entrepreneurship education in college of agriculture and natural resources in Iran. Journal of American Science, 7: 255-259.

13. Hezar jaribe, J. 2001. Entrepreneurship Development and Graduates. Research and Planning in Higher Education, 9: 159-177.

14. Karbasi, A., H. Asan Ashari and H. Aghel. 2009. Agricultural sector employment forecast in Iran. Journal of Economics in Agricultural Development, Agricultural Science and Technology, 22: 31-43.

15. Khosravi Pour, B. and S.H. kikhaah. 2013. Entrepreneurship Education, an Effective Approach to Employing Agricultural Students. Monthly Social, Economic, Scientific and Cultural Work and Society, 6: 26-39. 
16. Mardanshahi, M. and M. Roshanfar. 2015. Formulation of Agricultural Entrepreneurship Development Strategies among Agricultural and Natural Resources Graduates. Strategies for entrepreneurship in agriculture, 2: 1-10.

17. Martins, S., C. Couchi, L. Parat, C. Federico, D. Roberto and S. Maureen. 2004. Barriers to entrepreneurship and business creation. EEC/Act04/02, European Entrepreneurship Cooperation,

18. Mehralizadeh, Y. and S.A. Arman. 2008. A folliw up study of employability of public university graduates. Daneshvar, 14(26), Special Edition on Management, 9: 73-86 (In Persian).

19. Rahmanian Koushki, M., M. Chizari and A.H. Havasi. 2012. Investigating Effective Factors of Entrepreneurship Entrepreneurship in Agricultural Students of Ilam University. Entrepreneurship Development, 5: 125-144.

20. Rasouliazar, S., S.M. Hosseini, S.J.F. Hosseini and S.M. Mirdamadi. 2010. Effective mechanisms for design of agricultural advisory service network in West Azerbaijan province, Iran. World Applied Sciences Journal, 10: 1272- 1278.

21. Saidi kia, M. 2003. Principles of Entrepreneurship. Tehran,

22. Shiri, N., D. Mohammad and S.M. Hosseini. 2012. Entrepreneurial Intention of Agricultural student: Effects of Role model, Social Support, Social Norms and Perceived Desirability. Scholars research Library, Archives of Applied Science Research, pp: 892-897.

23. Sobhanian Nezhad, L. 2011. Study of the reasons for non-employment of agricultural graduates and its solutions. National Conference on Employment of Agricultural and Natural Resources graduates. 2 and 3 December 2011 Tarbiat Modares University,

24. Sharifi, O., A. Asadi, R. Rezai and M. Adeli. 2010. Academic female entrepreneurship. Women's Research Journal, 1: 73-106.

25. Yaghobi, J. and P. Najaf Lu. 2016. Identification of Organizational Entrepreneurship Development Strategies in Agricultural Cooperatives (Case Study: Abhar County). Entrepreneurship in Agriculture, 4: 75-93

26.Zamani, GH. and T. Azizi Khalqili. 2007. Analysis of Executive Directors Concerning the Employment of Agricultural Graduates. Management research and agricultural training, 2: 36-46.

27. Zolali, N., B. Khosravi Pour and A. Zare. 2015. The Challenges and Challenges of Employment of Agricultural Graduates from the View of Executive Directors. Management research and agricultural training, 7: 73-83. 


\title{
Analysis the Role Playing of Agricultural and Natural Resources Engineering Organization in Development of Entrepreneurship Among Related Graduates in Khorramabad Township
}

\author{
Saeed Gholamrezai ${ }^{1}$, Fatemeh Sepahvand ${ }^{2}$, Karim Naderi Mehdi ${ }^{3}$ and Narges Kakolvand ${ }^{4}$
}

1- Assistant Professor, Dep of Rural Development, Lorestan University

(Corresponding Author: sgholamrezai@gmail.com)

2- Ph.D Student of Agricultural Development, Dep of Agricultural Extension and Education Bu-Ali Sina University

3- Associate Professor, Dep of Agricultural Extension and Education, Bu-Ali Sina University

4- Graduated Master in Rural Development, Dep of Rural Development, Lorestan University Received: March 3, 2018 Accept: July 17, 2018

\begin{abstract}
Purpose of this study was"Analysis the Role playing of Agricultural and Natural Resources Engineering Organization (ANREO) in the development of entrepreneurship among agricultural and natural resources sciences graduates in Khorramabad Township, Lorestan province.This qualitative research by Grounded theory (GT) in 2017. The statistical population in this research was the 24 members of this organization and through snowball sampling .Initially, the "mechanisms" were determined using the Glaser \& Strauss patterns. Then, using the MAXQDA 12 software, the main and secondary categories were extracted. The study continued on the basis of Strauss \& Corbin's paradigmatic model. The results showed that this organization could be more successful if it performed the following: By introducing entrepreneurs to the relevant institutions for contracting for the sale of their products, introducing the Small low credit enterprises, Needs assessment of members in field of related entrepreneurship subjects, providing consultative services to Proper loan.
\end{abstract}

Keywords: Agricultural and Natural Resources Engineering (ANRE), Entrepreneurship Development, Graduates, Lorestan 